Patients and method: During the period 2000-2012, 400 children suffering acute viral hepatitis were examined on Infective Diseases Clinic, Clinical Center of Montenegro, Podgorica. Complete history, route of infection, an abdominal ultrasound and standard biochemical tests were done. During the research we used virus tests sensible to: HAV, HEV, HBV, HCV, EBV. Research sample is consisting from 27 examinees of both sex, different ages with clinical, laboratory and virology verification and description of acute hepatitis E viral infection and 27 examiness with acute hepatitis A infection.

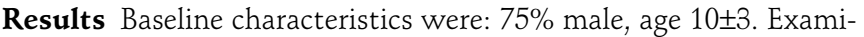
ness with infection HEV had most frequent symptoms loss appetite $70.8 \%$ and slackness $(66.6 \%)$ while examiness with HAV infection had retch $70 \%$ and loss appetite $100 \%$. Hepatomegaly, rice temperature were present at all examiness with hepatitis $\mathrm{A}$, while examiness with acute hepatitis $E$ had hepatomegaly at $66.6 \%$ cases and rice temperature at $45.8 \%$ race. Patients without symptoms was present in group with hepatitis E. (29\%). Increase spleen was more freguent at patients with acute hepatitis A. Values alaninaminotransferasis was higer at patients with acute hepatitis A. Rice of all patients with acute hepatitis E had Glutamat dehidrogenasis (GGT) twice higer than refferent values.

Conclusion Hepatitis E has many similarities with hepatitis A: enterically transmitted self-limited infections. We had important different of symptoms, clinic image and laboratory analysis between this both of virus hepatitis.

\section{EFFECT OF EARLY TOOTH EXTRACTION ON THE DURATION OF HOSPITALIZATION IN FACIAL CELLULITIS OF ODONTOGENIC ORIGIN IN CHILDREN}

doi:10.1136/archdischild-2012-302724.0870

${ }^{1} Y$ Ozsurekci, ${ }^{2} \mathrm{~A}$ Kara, ${ }^{2} \mathrm{M}$ Tekcicek, ${ }^{2} \mathrm{E}$ Karadag Oncel, ${ }^{2} \mathrm{AB}$ Cengiz, ${ }^{2} \mathrm{~S}$ Karahan, ${ }^{2} \mathrm{M}$ Ceyhan, ${ }^{2} \mathrm{M}$ Celik, ${ }^{2} \mathrm{~A}$ Ozkaya-Parlakay. ${ }^{1}$ Pediatric Infectious Disease, Hacettepe University; ${ }^{2}$ Hacettepe University, Faculty of Medicine, Ankara, Turkey

Purpose To investigate the clinical characteristics of pediatric facial cellulitis of odontogenic origin and the impact of early tooth extraction on the length of hospitalization in children.

Methods Medical records of all patients with a discharge diagnosis of facial cellulitis of odontogenic origin or buccal cellulitis were reviewed. Clinical characteristics, including age, sex, symptoms of infection, location of infection, type of tooth involved, length of hospitalization, and the timing of dental interventions, were gleaned. Variables were correlated to length of hospitalization.

Results A total of 106 children (62 boys and 44 girls) were diagnosed with facial cellulitis of odontogenic origin. Early tooth extraction (within $48 \mathrm{~h}$ ) and white blood cell count at admission were significantly associated with length of hospitalization ( $p=0.007$ and $p=0.03$, respectively). The length of hospitalization for upper face infections was significantly different than that for lower face infections $(p=0.01)$ and that for left face infections was significantly different than that for right face infections $(p=0.01)$. There was also a significant correlation between length of hospitalization and type of tooth involved $(p=0.01)$. Patients who had an infection of a primary first molar tooth had a shorter length of hospitalization.

Conclusion In the management of pediatric facial cellulitis of odontogenic origin, early tooth extraction may decrease the length of hospitalization. White blood cell count, site of infection, and the type of tooth involvement at admission have significant impacts on length of hospitalization.

\section{FREQUENCY OF NOROVIRUS INFECTION IN CHILDREN WITH ACUTE GASTROENTERITIS}

doi:10.1136/archdischild-2012-302724.0871
'S Biçer, 'D Çöl, ${ }^{2} \mathrm{O}$ Küçük, ${ }^{2} \mathrm{GÇ}$ Erdağ, ${ }^{2} \mathrm{~T}$ Giray, ${ }^{3} Y$ Gürol, ${ }^{4} \mathrm{M}$ Uğraş, ${ }^{2} \mathrm{~A}$ Vitrinel, ${ }^{3} \mathrm{G}$ Çelik. ${ }^{1}$ Child Health and Diseases; ${ }^{2}$ Child Health and Pediatrics; ${ }^{3}$ Medical Microbiology; ${ }^{4}$ Child Health and Pediatrics, Child Gastroenterology, Yeditepe Univ Medical Faculty, Istanbul, Turkey

Background and Aims Noroviruses are one of the common causes of acute gastroenteritis and have a great impact on child health. The aim of this study was to determine the prevalence of Norovirus in children with acute gastroenteritis in 2009 and 2010.

Methods Fecal samples were collected from children under 16 years of age who were suffering from acute gastroenteritis. All the children were referred to Yeditepe University Hospital, located in Istanbul. Norovirus was detected using immunochromatography.

Results Norovirus infection was detected in 112 of the 1027 collected samples $(10.9 \%)$. Most of the positive cases were between 1 and 24 months of age $(n=75,67 \%)$. The rate of norovirus infection peaked in winter in 2010 (in winter and spring: $n=57,92 \%$ ), however, the rates were not significantly different between seasons in 2009 (in winter and spring: $n=26,52 \%$, in summer: $n=23,46 \%$ ). We did not detect any positive cases in late summer and autumn in 2010.

Conclusions This study improves our epidemiological knowledge of the prevalence of Norovirus in Istanbul. Immunochromatography is preferable, that provides rapid diagnosis. The prevalence of Norovirus is similar but seasonal distribution is different between two years. Most of the cases were $<24$ months of age. Because this virus is transmitted by contaminated food or water, and transmitted by personal contact, we recommend improved training in hygiene to reduce the incidence of Norovirus infection in children. Like Rotavirus, Norovirus vaccine can be developed to prevent infection.

\section{NEONATE SKIN LACERATION DURING DELIVERY AS IATROGENIC RISK FACTOR OF MOTHER-TO-CHILD HCV INFECTION}

doi:10.1136/archdischild-2012-302724.0872

'M Aniszewska, 'B Kowalik-Mikolajewska, ${ }^{2} \mathrm{M}$ Pokorska-Spiewak, ${ }^{2} \mathrm{M}$ Pluta, 'M Marczynska. 'Department of Children's Infectious Diseases, Medical University of Warsaw, Regional Hospital of Infectious Diseases; ${ }^{2}$ Department of Children's Infectious Diseases, Regional Hospital of Infectious Diseases, Warsaw, Poland

HCV mother-to-child transmission occurs mainly in the peripartum period. Cesarean section delivery is not recommended as prevention of HCV neonate infection. Available data from professional centers are conflicting. There is no information about association between neonate laceration during delivery and HCV infection.

The Aim of the study was to establish the rate of neonate injury during delivery and the role of this complication in the risk of mother-to-child HCV transmission.

Methods We collected data of mode of delivery in the group of 392 children born to anti-HCV+ mothers: $34 \mathrm{HCV}$ infected children and 358 without HCV infection.

Results 235/392(60\%) children were delivered vaginally, $157 / 392(40 \%)$ by cesarean section. Skin laceration was observed in $9(2.3 \%)$ children: $4 / 235(1.7 \%)$ delivered vaginally, $5 / 157(3.2 \%)$ by cesarean section. In the group of HCV infected children $25 / 34(74 \%)$ were delivered vaginally, $9 / 34(26 \%)$ by cesarean section. The rate of HCV infection among children delivered vaginally was $25 / 235$ (10.6\%), by cesarean section 9/157(5.7\%). 5/9(55\%) children with skin laceration were HCV infected. In the group of children without skin laceration HCV infection was diagnosed in 29/383(7.5\%). There were 43 children delivered by elective cesarean section in $38 \mathrm{Hbd}$ and none of them was injured, none of them was HCV infected.

\section{Conclusions:}

1. Iatrogenic exposure to HCV during delivery may increase the risk of HCV mother-to-child infection. 